\title{
EFFECTIVE DIFFUSIVITY AND CONVECTIVE MASS TRANSFER COEFFICIENT DURING THE DRYING OF BANANAS
}

\author{
CLEIDE M. D. P. DA S. E SILVA ${ }^{1}$, WILTON P. DA SILVA ${ }^{2}$, VERA S. DE O. FARIAS ${ }^{3}$, \\ JOSIVANDA P. GOMES ${ }^{4}$
}

\begin{abstract}
In this article, a methodology is used for the simultaneous determination of the effective diffusivity and the convective mass transfer coefficient in porous solids, which can be considered as an infinite cylinder during drying. Two models are used for optimization and drying simulation: model 1 (constant volume and diffusivity, with equilibrium boundary condition), and model 2 (constant volume and diffusivity with convective boundary condition). Optimization algorithms based on the inverse method were coupled to the analytical solutions, and these solutions can be adjusted to experimental data of the drying kinetics. An application of optimization methodology was made to describe the drying kinetics of whole bananas, using experimental data available in the literature. The statistical indicators enable to affirm that the solution of diffusion equation with convective boundary condition generates results superior than those with the equilibrium boundary condition.
\end{abstract}

KEYWORDS: drying kinetics, algorithm optimization, diffusion, porous media.

\section{DIFUSIVIDADE EFETIVA E COEFICIENTE DE TRANSFERÊNCIA CONVECTIVO DE MASSA DURANTE A SECAGEM DE BANANAS}

RESUMO: Neste artigo, é usada uma metodologia para a determinação simultânea da difusividade efetiva e do coeficiente de transferência convectivo de massa em sólidos porosos que possam ser considerados como um cilindro infinito, durante sua secagem. Dois modelos são utilizados para a otimização e a simulação do processo de secagem: o modelo 1 (volume e difusividade constantes, com condição de contorno de equilíbrio); e o modelo 2 (volume e difusividade constantes, com condição de contorno convectiva). Algoritmos de otimização por varredura, baseados no método inverso, foram acoplados às soluções analíticas referentes aos dois modelos utilizados, possibilitando ajustar tais soluções aos dados experimentais da cinética de secagem em camada fina de produtos com a forma cilíndrica. Foi feita uma aplicação da metodologia de otimização na descrição da cinética de secagem de bananas inteiras, usando dados experimentais disponíveis na literatura. Os indicadores estatísticos relativos aos ajustes possibilitam afirmar que a solução da equação de difusão com condição de contorno convectiva produz resultados significativamente melhores que aqueles considerando a condição de contorno de equilíbrio.

PALAVRAS-CHAVE: cinética de secagem, algoritmo de otimização, difusão, meios porosos.

\section{INTRODUCTION}

Drying is a mechanism used in various fields of the productive sector, e.g. in food industry, wood, ceramic, pharmaceutical, and paper. The drying of a wet product may occur naturally or artificially. In the case of artificial drying, the most common method for agricultural products is to heat the air, reducing its relative moisture, and then transferring it to the environment in which it is placed in contact with the wet product. Therefore, there is a continuous process of heat transfer into the product. Simultaneously, there is a moisture transfer from the interior of the product to the

\footnotetext{
${ }^{1}$ Doutoranda em Engenharia de Processos, UAF/UFCG, Campina Grande - PB, Fone: (0XX83) 3333 2962, cleidedps@uol.com.br.

${ }^{2}$ Doutor, Prof. Associado, UAF/UFCG, Campina Grande - PB, wiltonps@uol.com.br.

${ }^{3}$ Doutora, Prof. Associado, UAE/UFCG, Campina Grande - PB, vera-solange@ uol.com.br.

${ }^{4}$ Doutora, Prof. Associado, UAEA/UFCG, Campina Grande - PB, josi@ deag.ufcg.edu.br.

Recebido pelo Conselho Editorial em: 13-5-2011
}

Aprovado pelo Conselho Editorial em: 10-11-2011 
surface and from the surface to the drying air in the form of steam. In general, the process of heat and mass transfer between the product and the mode may be described by means of the diffusion equation (LUIKOV, 1968). For the diffusion equation may be solved, it is necessary that the boundary condition between the mode and the external surface of the product to be known. In the drying of many agricultural products, by using hot air, it is verified that the most suitable boundary condition is the convective (QUEIROZ \& NEBRA, 2001; MARIANI et al., 2008; SILVA et al., 2010), although the condition of boundary of balance is also used to describe many of drying processes (AMENDOLA \& QUEIROZ, 2007; HACIHAFIZOGLU et al., 2008; SILVA et al., 2009).

To determine the effective diffusivity and the convective coefficient of mass transfer, often the solution of the diffusion equation is coupled to an optimizer that, in general, it is based on the inverse method (MARIANI et al., 2008; SILVA et al., 2008; DA SILVA et al., 2009; SILVA et al., 2009; SILVA et al., 2010; SILVA et al., 2011). DA SILVA et al. (2009) proposed two algorithms, one deterministic and other stochastic, in order to determine the effective diffusivity of mass in the drying of mushrooms, assuming the boundary condition of equilibrium and infinite wall geometry. SILVIA et al. (2009), assuming equilibrium boundary condition, proposed an optimizer that scans the area of the diffusivity in search of a minimum for the objective function and engaged such optimizer in analytical solution of the diffusion equation for the sphere. The advantage of the latter optimizer over other available in the literature is that, on this optimizer, it is not necessary to be stipulated an initial value or range of values for determining the variable of interest by the user. The review of the literature allows noting that there are few studies proposing optimization algorithms coupled with analytical solutions of the diffusion equation with convective boundary condition, particularly when many terms are used in the series that represents such solutions. In general, for the convective boundary condition, numerical solutions are used for describing the drying process. This finding contrasts with the abundant number of articles on the subject to the boundary condition of equilibrium. A possible reason for the lack of analytical solutions in the literature for the problem of diffusion with convective boundary condition may be a great amount of roots of the characteristic equation to be determined, so as to cover the whole area of the Biot number when many terms in the series are taken into account.

QUEIROZ \& NEBRA (2001) presented a study on the drying kinetics of entire bananas, using hot air under different conditions of temperature and relative moisture. To numerically simulate the drying kinetics using diffusion models with convective boundary condition, the authors used the method of finite differences. AMENDOLA \& QUEIROZ \& (2007) described the drying kinetics of bananas, individualizing the diffusion equation for an infinite cylinder, considering the volume and diffusivity constant, beyond the boundary condition of equilibrium. In this study, the authors used cylindrical coordinates and the method of finite differences. SILVA et al. (2008) described the drying kinetics of bananas and they assumed that the boundary condition of the first type was suitable for the drying process. From this point, a numerical methodology was proposed to solve the diffusion equation in cylindrical solids. The authors chose a decreased expression in which the diffusivity depends on the moisture content $\mathrm{X}$. Using an optimization algorithm and experimental data, the researchers determined the values of the parameters "a" and " $b$ ", minimizing the objective function defined by the chi-square of the adjustment. However, the authors recognized that if the boundary condition of equilibrium is not completely acceptable to describe the process of drying, the obtained difusity will only be interpreted as an expression which adjusts the numerical solution of the experimental data.

In this study, the description of the drying kinetics of entire bananas is made by using optimization algorithms coupled with analytical solutions of the diffusion equation for the infinite cylinder, assuming the boundary conditions of equilibrium and convective transport to the phenomenon being described. Comparison of the results allows pointing out the appropriate boundary conditions for the description of drying. In addition, enable the tools used to determine 
the effective diffusivity and the coefficient of convective mass transfer and also a detailed description of the drying process.

\section{MATERIAL AND METHODS}

In this paper, the liquid diffusion model was used to describe the drying of bananas in thin layer. In this case, the diffusion equation must be used in the process description.

\section{Diffusion equation}

In the description of a drying process, the diffusion equation of a solid whose geometry can be approximated by an infinite cylinder can be written as follows (LUIKOV, 1968; SILVA et al., 2011):

$$
\frac{\partial X}{\partial t}=\frac{1}{r} \frac{\partial}{\partial r}\left(r D_{\text {ef }} \frac{\partial X}{\partial r}\right)
$$

in which: $r$ defines the position of a point in relation to the central axis of the cylinder, $t$ is the drying time, $\mathrm{D}_{\text {ef }}$ is the mass effective diffusivity, and $\mathrm{X}$ is the moisture on a dry basis. Equation (1) may be solved numerically, and assuming certain hypotheses, it may also be solved analytically.

The determination of the analytical solution for eq.(1) assumes the following hypotheses: 1) the solid must be considered homogeneous and isotropic, 2) the distribution of moisture content inside the solid must be initially uniform, 3) the unique mechanism of transport of water into the solid is liquid diffusion, 4) the dimensions of the solid does not vary during the transmission, 5) the effective diffusivity does not vary during diffusion, 6) for the convective boundary condition, the convective transfer coefficient of mass does not varies during the diffusion.

\section{Analytical solution for the boundary condition of equilibrium}

For the boundary condition of the first type, the solution of eq.(1) is obtained by separation of variables and the results are given below (LUIKOV, 1968):

$$
X(r, t)=X_{e q}-\left(X_{e q}-X_{i}\right) \sum_{n=1}^{\infty} A_{n} J_{0}\left(\mu_{n} r / R\right) \exp \left(-\mu_{n}^{2} \frac{D_{e f}}{R^{2}} t\right)
$$

in which: $X(r, t)$ is the moisture content (dry basis) at a position $r$ in relation to the central axis of the cylinder in a time $t, X_{\text {eq }}$ is the moisture to $t \rightarrow \infty$, and $X_{i}$ is moisture to $t=0, R$ is the radius of cylinder, and $\mu_{\mathrm{n}}$ are the roots of the characteristic equation

$$
\mathrm{J}_{0}\left(\mu_{\mathrm{n}}\right)=0
$$

in which: $\mathrm{J}_{0}$ is relating to Bessel function of the first type and zero order. The coefficient $A_{n}$ is defined as follows:

$$
A_{n}=\frac{2}{\mu_{n} J_{1}\left(\mu_{n}\right)}
$$

in which: $\mathrm{J}_{1}$ is a Bessel function of first type and order one.

The mean value $\bar{X}(t)$ of $X(r, t)$, for a given time $t$, is determined by the expression:

$$
\bar{X}(t)=\frac{1}{V} \int X(r, t) d V
$$

in which: $\mathrm{V}$ is the volume of the cylinder. 
The solution of the diffusion equation for the mean value $\bar{X}(t)$ in an infinite cylinder is obtained by substituting eq.(2) into the eq.(5), and the result is:

$$
\bar{X}(t)=X_{e q}-\left(X_{e q}-X_{i}\right) \sum_{n=1}^{\infty} \frac{4}{\mu_{n}^{2}} \exp \left(-\mu_{n}^{2} \frac{D_{\text {ef }}}{R^{2}} t\right)
$$

\section{Analytical solution for the convective boundary condition}

The convective boundary condition is expressed by the imposition of equality between the internal flow (diffusive) on the boundary of the infinite cylinder and the external flow (convective) in the vicinity of this boundary, by the expression:

$$
-\left.\mathrm{D}_{\mathrm{ef}} \frac{\partial \mathrm{X}(\mathrm{r}, \mathrm{t})}{\partial \mathrm{r}}\right|_{\mathrm{r}=\mathrm{R}}=\mathrm{h}\left[\left.\mathrm{X}(\mathrm{r}, \mathrm{t})\right|_{\mathrm{r}=\mathrm{R}}-\mathrm{X}_{\mathrm{eq}}\right]
$$

in which: $h$ is the coefficient of mass convective transfer.

The solution of eq.(1) for the boundary conditions defined by eq.(7) is also obtained by separation of variables and results in (LUIKOV, 1968):

$$
X(r, t)=X_{e q}+\left(X_{i}-X_{e q}\right) \sum_{n=1}^{\infty} A_{n} J_{0}\left(\mu_{n} r / R\right) \exp \left(-\mu_{n}^{2} \frac{D_{e f}}{R^{2}} t\right)
$$

in which

$$
A_{n}=\frac{2 B i}{J_{0}\left(\mu_{n}\right)\left[\mu_{n}^{2}+B i^{2}\right]}
$$

The parameter $\mathrm{Bi}$ is the Biot number for the transfer of mass, $\mu_{n}$ are the roots of the characteristic equation for the infinite cylinder with convective boundary condition and they are respectively defined as the following equations:

$$
\mathrm{Bi}=\frac{\mathrm{hR}}{\mathrm{D}_{\text {ef }}}
$$

and

$$
\frac{J_{0}\left(\mu_{n}\right)}{J_{1}\left(\mu_{n}\right)}=\frac{\mu_{n}}{B i}
$$

Substituting the eq.(8) into the eq.(5), it is obtained the following expression for the mean moisture content $\overline{\mathrm{X}}(\mathrm{t})$ of the cylindrical solid in an instant $\mathrm{t}$ :

$$
\bar{X}(t)=X_{e q}+\left(X_{i}-X_{e q}\right) \sum_{n=1}^{\infty} B_{n} \exp \left(-\mu_{n}^{2} \frac{D_{e f}}{R^{2}} t\right)
$$

in which: the coefficient $B_{n}$ is given by

$$
\mathrm{B}_{\mathrm{n}}=\frac{4 \mathrm{Bi} \mathrm{i}^{2}}{\mu_{\mathrm{n}}^{2}\left(\mathrm{Bi}^{2}+\mu_{\mathrm{n}}^{2}\right)}
$$

In order to determine $\overline{\mathrm{X}}(\mathrm{t})$ by eq.(12) for a given Biot number, it was created a Fortran program on that calculates the first 30 roots $\mu_{n}$ of the characteristic equation defined by eq.(11). In this program, it has been specified different Biot numbers 452, covering the region from 0 (corresponding to an infinite resistance to the flow of water on the surface) up to 200 
(corresponding to a boundary condition of equilibrium). Then, for each Biot number, the first 30 roots of eq.(11) were determined. Obviously, the performed calculations resulted in a large database with 13,560 values of roots. The determination of all these roots and their structure in a subroutine that enables the optimization process is an arduous task due to the required time for its implementation. However, as it will be seen below, the computational implementation is a relatively simple task.

\section{Optimizer for the analytical solution with boundary condition of equilibrium}

SILVA et al. (2009) proposed an algorithm for an optimizer using the scanning of the area to determine the diffusivity of water for drying described by diffusion equation with boundary condition of equilibrium. The objective function defined by the authors was the chi-square regarding the adjustment curve simulated to experimental data (SILVA et al., 2009):

$$
\chi^{2}=\sum_{i=1}^{N_{p}}\left[\bar{X}_{i}^{\text {exp }}-\bar{X}_{i}^{\text {ana }}\left(D_{\text {ef }}\right)\right]^{2} \frac{1}{\sigma_{i}^{2}}
$$

in which: $\overline{\mathrm{X}}_{\mathrm{i}}^{\exp }$ is the mean moisture content measured experimentally, referring to the point $\mathrm{i}$; $\bar{X}_{i}^{\text {ana }}\left(D_{\text {ef }}\right)$ is the mean moisture content corresponding to the point $i$ obtained by analytical solution of the diffusion equation; $\sigma_{i}$ is the standard deviation of the mean moisture content measured experimentally referring to the point $\mathrm{i}$; $\mathrm{D}_{\mathrm{ef}}$ is the effective diffusivity, and $\mathrm{N}_{\mathrm{p}}$ is the number of experimental points. For the boundary condition of the first type, the chi-square parameter depends on a single of process, which is the effective diffusivity. Thus, for each set of experimental data, an optimum " $\mathrm{D}_{\mathrm{ef}}$ " may be determined by minimizing the chi-square, used as the objective function. If $\sigma_{\mathrm{i}}$ is not known, that is, if not obtained in the performed experiments, this parameter must be made equal to 1 for all the experimental points, i.e. all points must have the same statistical weight $1 / \sigma_{i}^{2}$.

Equation (14) gives the chi-square in function of the diffusivity value, which is the parameter to be determined. In the algorithm proposed by SILVA et al. (2009), it is neither necessary for the user to assign an initial value of the parameter to be determined, nor to stipulate a range of search for an optimum "Def". Essentially, SILVA et al. (2009) proposed the following steps:

1- Initially it is assigned a value near zero $\left(1 \times 10^{-20}\right)$ to $D_{\text {ef }}$, which is substituted in the Equation (6) with a certain number of terms in the series. Thus, $\bar{X}_{i}^{\text {ana }}\left(D_{\text {ef }}\right)$ may be calculated during the time of interest, which allows determining a set $\chi^{2}$ of experimental data given by eq.(14). Then, the value of $D_{\text {ef }}$ is doubled and a new $\chi^{2}$ is calculated. The new chi-square is compared with the previous value. If the new value is lower, $D_{\text {ef }}$ is doubled again, and another value for $\chi^{2}$ is calculated, followed by comparison with the previous value. This procedure is repeated until the last $\chi^{2}$ calculated is greater than the previous value. Thus, the penultimate and last values of $D_{\text {ef }}$, respectively denoted by $D_{a}$ and $D_{b}$, define a gross region that contains the minimum value of $\chi^{2}$.

2- The range defined by the penultimate and last values of $D_{\text {ef }}$ is divided by an integer $n$, establishing new values for the effective diffusivity. Such values are substituted into the equation solution of diffusion, followed by calculation $\bar{X}_{i}^{\text {ana }}\left(D_{\text {ef }}\right)$ which enables to determine $\chi^{2}$ by eq.(14). Every new $\chi^{2}$ must then be compared with the value calculated previously, until a new minimum is determined.

3- Step 2 is repeated until a convergence criterion for the effective diffusivity is reached. 
It must be observed that with a number of scans between 50 and 60 times, in general, effective diffusivity is determined with good accuracy. Therefore, the computational effort is minimal and, generally, less than 10 seconds are required to determine optimum effective diffusivity.

\section{Optimizer for the analytical solution with convective boundary condition}

When the boundary condition is convective, eq.(12) must be used in the description of the kinetics of drying of cylindrical solids. Thus, the objective function to be minimized is expressed as follows (SILVA et al., 2010):

$$
\chi^{2}=\sum_{i=1}^{N_{p}}\left[\bar{X}_{i}^{\text {exp }}-\bar{X}_{i}^{\text {ana }}\left(D_{\text {ef }}, B i\right)\right]^{2} \frac{1}{\sigma_{i}^{2}}
$$

The objective function given by eq.(15) depends on the effective diffusivity and also the Biot number for mass transfer or, equivalently, the convective coefficient mass transfer. Moreover, for a specified number of Biot, eq.(15) function only becomes of the effective diffusivity. Thus, eq.(15) becomes equivalent to eq.(14). Therefore, the optimizer developed by SILVIA et al. (2009) may be applied to the minimization of eq.(15), determining an optimum value for the effective diffusivity related to the specified number of Biot. Assuming that the effective diffusivity $D_{\text {ef }}$ and convective transfer coefficient of mass $h$ are independent parameters of each other, the procedure of minimizing presented may be repeated for all the 452 Biot numbers covering the field from 0 to 200. After scanning all Biot numbers, must be made the identification of the lowest chi-square among 452 minimum determined. It is noteworthy that, as the entire field of Biot number for mass transfer is scanned, it is not necessary the initial values or ranges of values are stipulated for the search for optimum values for $\mathrm{D}_{\mathrm{ef}}$ and $\mathrm{Bi}$, and consequently $\mathrm{h}$.

Once the effective diffusivity and Biot number has been determined by this last optimization algorithm proposed for a number of experimental data, eq.(8) may be used to determine the distribution of moisture of the cylindrical solid as a function of radius $r$, between 0 and $\mathrm{R}$, for a given instant in time. Since the eq.(12) must be used to describe the kinetics drying of the product under consideration.

The optimizers presented in this article to be coupled to the analytical solutions concerning the infinite cylinder were developed in an Intel Pentium IV with 1 GB (RAM). The source code compilation was performed in the studio Compaq Visual Fortran (CVF) Professional Edition 6.6.0; using option named QuickWin Application a programming, while the platform was Windows XP. Moreover, the analytical solutions of the diffusion equation for infinite cylinder were given by the first 30 terms of the eq.(6) and (12) which relate the mean value of $X$ and a given time t. The convergence criteria stipulated for the determination of the diffusivity for a specified Biot number was $1 \times 10^{-15}$.

Statistical analysis of the obtained results was performed by LAB Fit Curve Fitting Software (www.labfit.net). In analyzing the results, statistical indicators were used as determination coefficient $\mathrm{R}^{2}$ and the chi-square $\chi^{2}$ (SILVA et al., 2009). Moreover, in the scanning process of experimental data available in literature was used xyExtract Graph Digitizer software (http://zeus.df.ufcg.edu.br/labfit/index_xyExtract.htm).

\section{Experimental data}

Optimizers coupled to analytical solutions for the infinite cylinder were used to determine the effective diffusivity and the convective coefficient transfer of mass concerning the available experimental data in SILVA et al. (2008) for the drying of banana on a thin layer using warm air. The initial moisture content and the balance of the product were $X_{i}=3.214$ (b.s.) and $X_{e q}=0.0559$ (b.s.) respectively, the drying air temperature was $50{ }^{\circ} \mathrm{C}$ with relative moisture of $20 \%$ and air velocity was maintained at $1.5 \mathrm{~m} \mathrm{~s}^{-1}$. SILVIA et al. (2008) consider all the statistical weight equal to 
1 , which was also done in this article. Moreover, the radius of the banana is $\mathrm{R}=1.522 \mathrm{~cm}$, and the product were considered an infinite cylinder.

Naturally, the moisture content in dimensionless form allows a better interpretation of the kinetics of drying, particularly when multiple kinetics, with different initial moisture contents are presented in the same system of axes. However, this study uses the methodology previously presented to a single set of data. Thus, the presentation of moisture content on dry basis shall not bring any problem to the interpretation of the obtained results. Furthermore, the statistical indicators herein obtained, for example, the chi-square, may be directly compared with those obtained by SILVA et al. (2008), using a numerical solution with boundary condition of the first type and variable diffusivity to describe the kinetics of drying also using the experimental data on a dry basis.

\section{RESULTS AND DISCUSSION}

\section{Boundary conditions of equilibrium}

Using the algorithm provided by SILVA et al. (2009) for the optimization of diffusive processes with boundary condition of equilibrium coupled to the first 30 terms of eq.(6), the adjustment is obtained as shown in Figure 1.

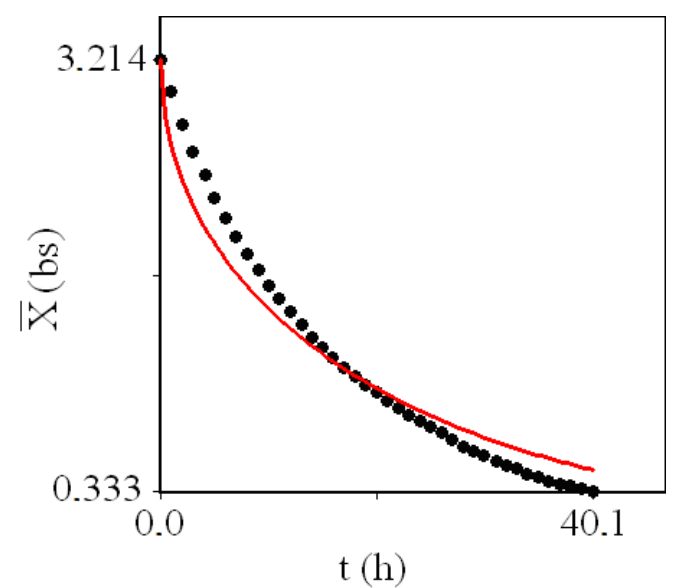

FIGURE 1. Drying kinetics of banana for the equilibrium boundary condition.

Considering the number of infinite Biot, $D_{\text {ef }}=4,567 \times 10^{-10} \mathrm{~m}^{2} \mathrm{~s}^{-1}\left(\mathrm{D}_{\mathrm{ef}}=1,644 \times 10^{-6} \mathrm{~m}^{2} \mathrm{~h}^{-1}\right)$, was obtained with the statistical indicators for the adjustment of data by $\mathrm{R}^{2}=0.987774$ and $\chi^{2}=$ 1.1734. The statistical indicator of adjustment $\chi^{2}$ is not considered satisfactory and, therefore, SILVIA et al. (2008) proposed a variable diffusivity according to the moisture content, local aiming to adjust the numerical solution to the experimental data, maintaining the of equilibrium boundary condition for the diffusive process. But, as the authors admitted in their study, this procedure must be interpreted merely as a feature to adjust the numerical solution to the experimental data, using the boundary condition of equilibrium. In this paper, instead of opting for the numerical solution with boundary condition of equilibrium and variable diffusivity, such boundary condition is discarded in the description of the entire bananas drying.

\section{Convective boundary condition}

Coupling the first 30 terms of eq.(12) to the optimization algorithm proposed by SILVIA et al. (2010) for the convective boundary condition, and adjusting this equation to the experimental data, a range of results is obtained for the various estipulated numbers of Biot of mass transfer. Thus, one may establish a relationship between the chi-square $\left(\chi^{2}\right)$ of each adjustment and the corresponding Biot number, (Bi), specified from 0 to 200 . The graph showing $\chi^{2}$ versus Bi for the experimental data of banana drying may be observed in Figure 2. 


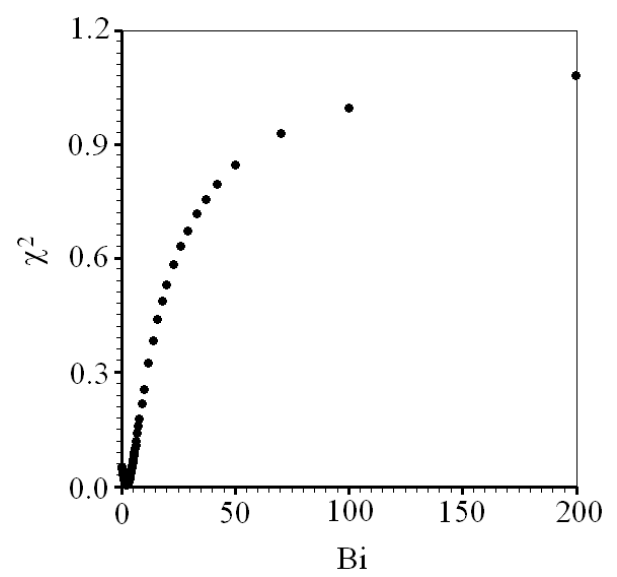

FIGURE 2. Chi-square versus the Biot number for the specified values between 0 and 200.

An inspection of Figure 2 allows concluding that the lowest chi-square corresponds to a Biot number, between 0 and 5. Thus the graph of Figure 2 may be extended in this region, which is the region near the minimum value to $\chi^{2}$, as shown by Figure 3.

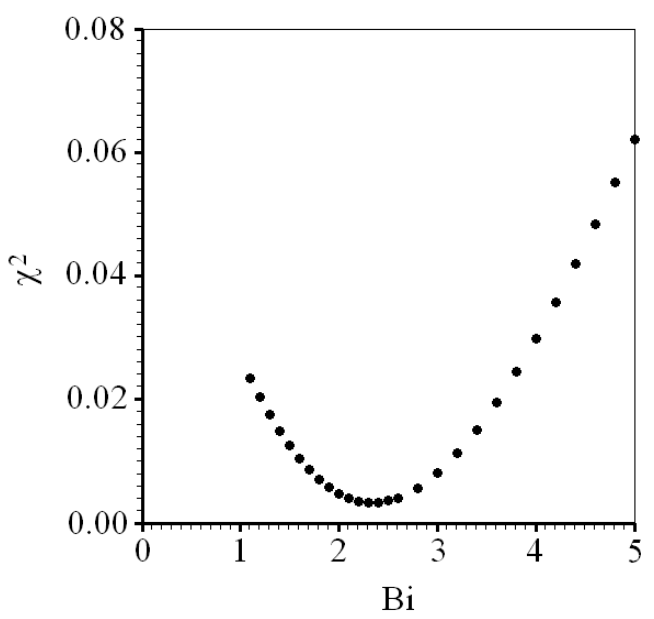

FIGURE 3. Highlight for chi-square versus the Biot number in the vicinity of the optimal point.

For the experimental data of banana drying, the Biot number, related to the lower chi-square is $\mathrm{Bi}=2.35$, corresponding to an effective diffusivity $D_{\text {ef }}=1.336 \times 10^{-9} \mathrm{~m}^{2} \mathrm{~s}^{-1}\left(\mathrm{D}_{\mathrm{ef}}=\right.$ $4.811 \times 10^{-6} \mathrm{~m}^{2} \mathrm{~h}^{-1}$ ), which allows to calculate the coefficient of convective transfer of mass: $\mathrm{h}=$ $2.064 \times 10^{-7} \mathrm{~m} \mathrm{~s}^{-1}\left(\mathrm{~h}=7.429 \times 10^{-4} \mathrm{~m} \mathrm{~h}^{-1}\right)$. Thus, it is possible to design a graph representing the kinetic of bananas drying, also showing the experimental data, which is done in Figure 4.

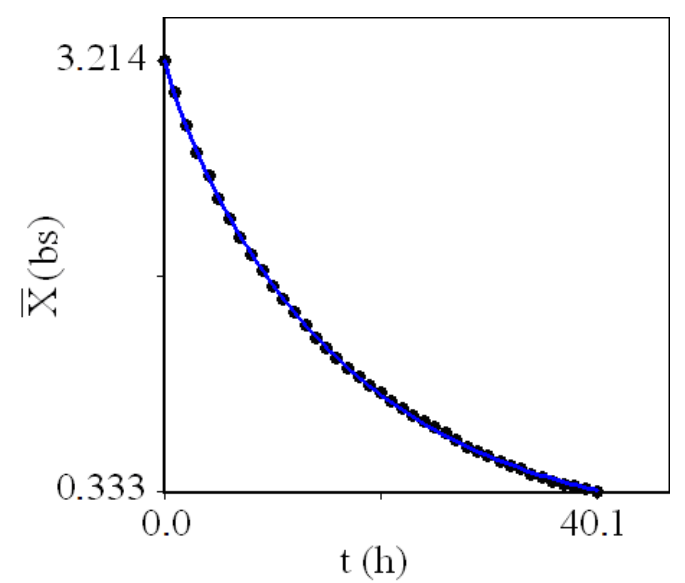

FIGURE 4. Drying kinetics of banana for the convective boundary condition. 
The indicators of the adjustment, obtained through the optimization methodology used in this study are as follows: $\mathrm{R}^{2}=0.999880$ and $\chi^{2}=3,2443 \times 10^{-3}$. An overview of all the results may be seen in Table 1.

TABLE 1. Optimal parameters and statistical indicators for the two boundary conditions considered for describing the banana drying.

\begin{tabular}{clccc}
\hline & $\mathrm{D}_{\text {ef }}\left(\mathrm{m}^{2} \mathrm{~s}^{-1}\right)$ & $\mathrm{h}\left(\mathrm{m} \mathrm{s}^{-1}\right)$ & $\mathrm{R}^{2}$ & $\chi^{2}$ \\
\hline First type & $4.567 \times 10^{-10}$ & - & 0.987774 & 1.1734 \\
Third type & $1.336 \times 10^{-9}$ & $2.064 \times 10^{-7}$ & 0.999880 & $3.2443 \times 10^{-3}$ \\
\hline
\end{tabular}

Differently from many grains, the boundary condition of equilibrium is successfully used in the description of kinetics of drying (BROOKER, 1992), in the case of bananas, an inspection on Table 1 indicates that the condition of equilibrium is inappropriate when compared with the convective boundary condition.

\section{Discussion}

While studying the kinetics of drying of paddy rice, SILVIA et al. (2010) showed that, although the appropriate boundary conditions for the diffusion process was convective, the boundary condition of equilibrium was also acceptable to describe such process. However, in the case of bananas drying, considering the constant diffusivity, the convective boundary condition is most suitable for describing the diffusion process as it will be seen through the following discussion.

Figure 4 and Table 1 make possible to state that the diffusion equation for infinite cylinder with boundary condition describes satisfactorily convective drying process. As shown on Table 1, the statistical indicators relating to the obtained results, considering the convective boundary condition, are significantly better than those in which the boundary condition of equilibrium is considered. For example, the chi-square of the adjustment concerning the optimization with convective boundary condition is reduced 362 times in relation to the optimization considering the boundary condition of the first type.

With the parameters of the kinetics of drying already determined, Equation (8) allows to determine the moisture content at the boundary of the infinite cylinder and also at the center. The mean value of moisture content may be calculated by Equation (12). An idea about how the three moisture contents mentioned are different, in each instant of time, may be given by Figure 5 .

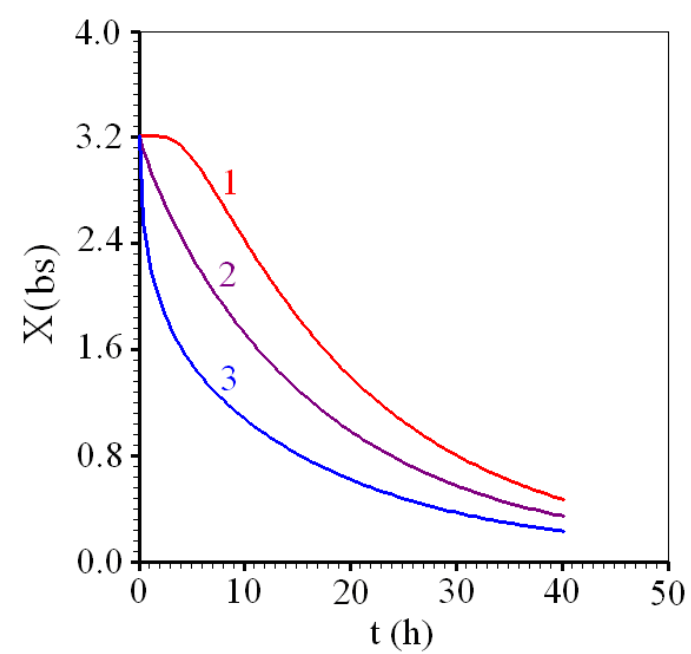

FIGURE 5. Moisture contents: (1) in the centre, using eq.(8); (2) average, using eq.(12); (3) on the boundary, using eq.(8). 
Information on how different is the moisture content in the center and the boundary of the cylinder is important because such differences generate water pressures that may damage the product. The maximum difference between these levels of moisture occurs at $t=5.213 \mathrm{~h}$ and worth 1.55611b.s. (3.02042b.s. in the center, and 1.46431b.s. in the boundary).

An inspection of the curve (3) of Figure 5 indicates that, in boundary, the moisture content does not assume the value of the moisture content of equilibrium instantly and, actually the boundary condition of the third type must be used in the description of process.

A contour plot showing the radial distribution of moisture content at time $t=5.213 \mathrm{~h}$ is shown by Figure 6.

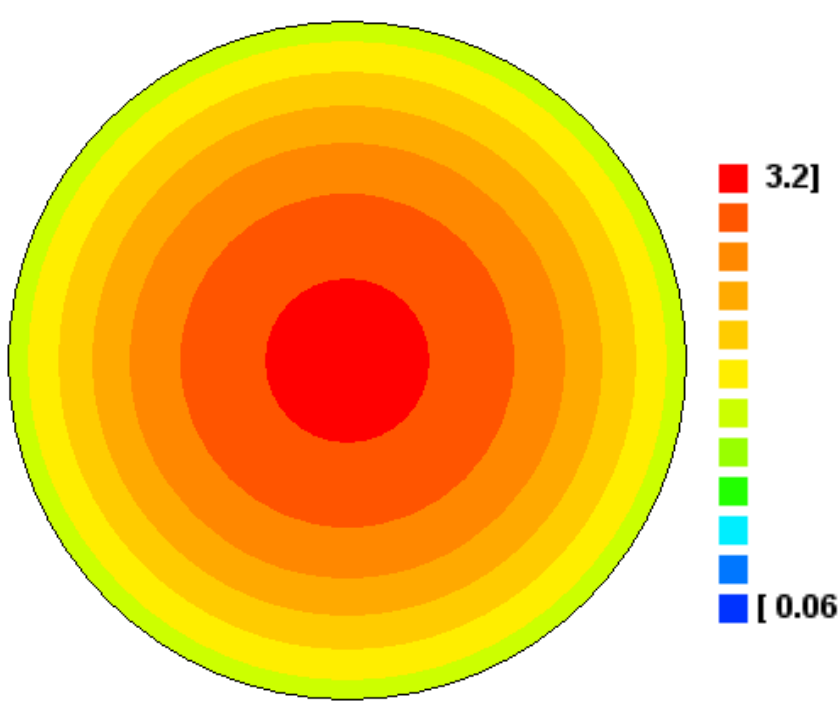

FIGURE 6. Radial distribution of moisture in the banana at $\mathrm{t}=5.213 \mathrm{~h}$.

A quantitative idea about the distribution of moisture content along the radius at time $\mathrm{t}=$ 5.213 h may be given by Figure 7, which shows the moisture content of the local depending on the radial position.

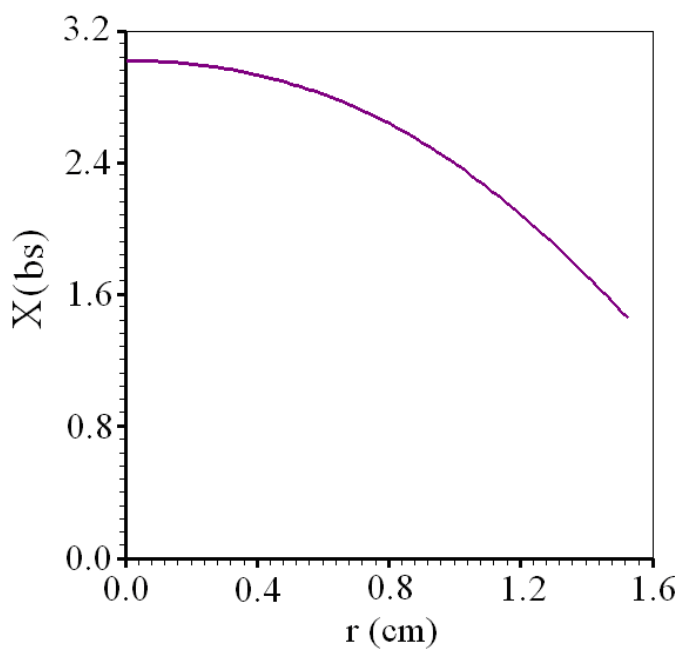

FIGURE 7. Radial distribution at $\mathrm{t}=5.213 \mathrm{~h}$.

In many drying processes of solid, cylindrical as in the case of bananas, the shrinkage is so significant that this effect could not be disregarded in the description of such process. In addition, it may happen that the thermo-physical parameters are variable. In such cases, the analytical solution is not appropriate to describe the diffusion process, which may best be described by numerical 
solutions. But even in these cases, the proposed optimization and coupled to the analytical solution of the diffusion equation for an infinite cylinder is useful because, through the proposed methodology, results which serve as initial values for other optimization processes can be extracted, particularly when this process involves the numerical solution of diffusion equation.

A question which could be made about the results obtained in the description of the kinetics of diffusion equation drying by means of condition of with convective boundary is as follows: if there is a strong shrinkage during drying process, which was not considered, why are the results so good? A possible explanation is as follows: during the drying process occurs a strong shrinkage of the product and occurs also a modification of the effective diffusivity of mass because of the modifications in the internal structure of the product due to shrinkage. As these two phenomena were not considered simultaneously in the assumptions made for mathematical modeling, it is possible that their effects are mutually canceled.

Although the determination of the roots of the characteristic equation of the infinite cylinder and its organization on "tables accessible" to the developed software is an arduous task, the computational implementation of the algorithm is quite simple and this is a favorable feature of the methodology presented in this article. Moreover, the run-time developed software strongly depends on the number of experimental data used to perform the adjustment. In this case, for example, a set

of 41 pairs $(t, \bar{X})$, the total time demanded for determining the parameters was 28 seconds. Although this time may be considered high, the possible slowness of the process is compensated by the fact that the computational implementation of the algorithm is very simple since it has been determined all the roots of the characteristic equation concerning the infinite cylinder. Moreover, in the optimization process, there is no need for the user to inform the initial values or ranges of values for the parameters to be determined, which is a very useful feature for facilitating such optimization process, whereby the user algorithm only inform the set of experimental data.

\section{CONCLUSIONS}

According to this study, the outer surface of the body does not come into balance with the drying air immediately. Thus, in the description of banana drying, the appropriate boundary condition for the problem is the convective, which considers the resistive effect with respect to the flow of moisture on the surface of the solid.

As noted, the statistical indicators regarding to the adjustment considering the convective boundary condition are better than that considering the boundary condition of equilibrium. The coefficient of determination increased from 0.987774 to 0.999880 , while the chi-square increased from 1.1734 to $3.2443 \times 10^{-3}$. Under the point of view of the duration of the optimization process, the running time increased from about 8 seconds (boundary condition of equilibrium) to 28 seconds (convective boundary condition).

Regarding the optimization algorithm used for the determination of $\mathrm{D}_{\mathrm{ef}}$ and $\mathrm{h}$, it may conclude that this algorithm produces consistent results with the expected values for these parameters. The main advantage of this algorithm is that it is not necessary to inform the initial values (or ranges of values) to the parameters to be determined by the user. For involving analytical solution, the disadvantage of the methodology is the imposition of volume and constant thermo-physical parameters during the drying process. But even when these parameters are variables, the obtained results by means of this methodology may be used as initial values in other optimization processes which include these restrictions.

\section{REFERENCES}

AMENDOLA, M.; QUEIROZ, M. R. Mathematical methodologies for calculating the mass diffusion coefficient of bananas during drying. Revista Brasileira de Engenharia Agrícola e Ambiental, Campina Grande, v.11, n.6 p.623-627, 2007. 
BROOKER, D. B.; BAKKER-ARKEMA, F. W.; HALL, C. W. Drying and storage of grains and oilseeds. Westport: The AVI Publishing Company, 1992. $450 \mathrm{p}$.

DA SILVA, C. K. F.; DA SILVA, Z. E.; MARIANI, V. C. Determination of the diffusion coefficient of dry mushrooms using the inverse method. Journal of Food Engineering, Essex, v.95, n.1, p.1-10, 2009.

HACIHAFIZOGLU, O.; CIHAN, A.; KAHVECI, K.; LIMA, A. G. B. A liquid diffusion model for thin-layer drying of rough rice. European Food Research and Technology, Berlin, v.226, n.4, p.787-793, 2008.

LUIKOV, A. V. Analytical heat diffusion theory. London: Academic Press, 1968. 685 p.

MARIANI, V. C.; LIMA, A. G. B.; COELHO, L. S. Apparent thermal diffusivity estimation of the banana during drying using inverse method. Journal of Food Engineering, Essex, v.85 n.4, p.569579, 2008.

QUEIROZ, M. R; NEBRA, S. A. Theoretical and experimental analysis of the drying kinetics of bananas. Journal of Food Engineering, Essex, v.4, n.2, p.127-132, 2001.

SILVA, W. P.; PRECKER, J. W.; SILVA, C. M. D. P. S.; GOMES, J. P. Determination of effective diffusivity and convective mass transfer coefficient for cylindrical solids via analytical solution and inverse method: Application to the drying of rough rice. Journal of Food Engineering, Essex, v.98, n.3, p.302-308, 2010.

SILVA, W. P.; PRECKER, J. W.; SILVA, C. M. D. P. S; SILVA, D. D. P. S. Determination of the effective diffusivity via minimization of the objective function by scanning: application to drying of cowpea. Journal of Food Engineering, Essex, v.95, n.2, p.298-304, 2009.

SILVA, W. P.; SILVA, C. M. D. P. S.; LINS, M. A. A. Determination of expressions for the thermal diffusivity of canned foodstuffs by the inverse method and numerical simulations of heat penetration. International Journal of Food Science and Technology, Oxford, v.46, n.4, p.811-818, 2011.

SILVA, W. P.; SILVA, C. M. D. P. S.; NASCIMENTO, P. L.; CARMO, J. E. F.; SILVA, D. D. P. $\mathrm{S}$. Influence of the geometry on the numerical simulation of the cooling kinetics of cucumbers. Spanish Journal of Agricultural Research, Madrid, v.9, n.1, p.242-251, 2011.

SILVA, W. P.; SILVA, C. M. D. P. S.; SILVA, D. D. P. S.; SILVA, C. D. P. S. Numerical simulation of the water diffusion in cylindrical solids. International Journal of Food Engineering, Essex, v.4, n.2, p.1-16, 2008. 